\title{
The National Council for the Care of Cripples in
}

\section{South Africa-}

\section{Its Relationship to Present-day Orthopaedic Servives.}

\begin{abstract}
A the turn of the century, many people in South Africa A were still clinging to traditional superstitions, and it is not difficult to understand why those who were deeply religious held misconceptions of divine intention. Attributing deformities and crippledom to God's will, and thus something to be born with fortitude, they regarded as impious, any effort toward alleviation or correction of the affliction.
\end{abstract}

Another aspect hindering the progress of orthopaedic service, as we know it to-day, is an equally sad one, and still present in the 1950's - that of a sense of disgrace, or intense embarrassement among the less enlightened resulting in this type of parent hiding their crippled child.

Thus ignorance played an important role and even to-day ignorance of available facilities and the sometimes almost miraculous results obtainable is a stumbling block, that the National Council for the Care of Cripples is working toward removing.

In the early part of the century as far as can be ascertained one of the first, if not the very first, medical man in the Union, who had had orthopaedic training overseas, was engaged in general practice but devoted as much time as scope permitted, to orthopaedics.

The phrase, 'as scope permitted' is very significant.

It was sarcely 30 years ago, that another orthopaedic surgeon, trained overseas, returned to South Africa and shortly afterwards was appointed visiting orthopaedist to the new Somerset Hospital in the Cape-the first orthopaedist to be associated with a public hospital, in the Union.

Without following the slow progress through in detail, even as orthopaedists gradually settled in South Africa their services were not fully used owing to reluctance of hospitals to spare beds for long term orthopaedic cases, and lack of other institutions prepared to accept these patients, especially children. As is known, some of these cases require many years of supervision nursing and care and more than one operation, and in the meantime education. As adolescence proceeds, training for their future became a further problem to be provided for.

In 1937 then, the rudimentary services, bound voluntary organisations in Cape Town, Johannesburg and Bloemfontein, struggling against great odds: lack of personnel, practically no facilities for artificial limbs or orthopaedic appliances and no adequate financial resources, plus public ignorance and apathy.

The very newly established orthopaedic centres in Cape Town and Johannesburg were the only places in the Union where a crippled person could receive treatment from an orthopaedic surgeon, and there were but three of them in the whole country! There was at the time too almost complete lack of orthopaedic facilities for the NonEuropean.

Then came Lord Nuffield's splendid gift of more than $£ 100,000$ to South Africa "toward a living organisation, rather than be spent on buildings". His technical advisor, an eminent orthopaedist, visited the Union and in drafting his recommendations he stated that Lord Nuffield recognised that the problem was an immense one, and that his gift could best be used as a stimulus and aid toward development of a National orthopaedic service, and among his detailed recommendations were:
"One organisation to cover the Union-an agreed Union Policy which should as far as possible influence Provincial administration.

1. A central Council.

2. Orthopaedic Hospital accommodation.

3. Orthopaedic Departments in all 1st grade General Hospitals.

4. Specialist staff and financial provision for the same."

There were a host of other aspects recommended, too numerous to mention in this article, but that to-day are taken for granted as part of Orthopaedic service.

The 'Central Council' then came into being in 1939, and was known as the National Council for the Care of Cripples in South Africa.

The task of co-ordinating, prodding and negotiating that lay ahead of it, was stupendous, added to that was the great need for propaganda with a capital $P$ and fundraising on a National basis.

To this end the Easter Stamp Fund was inaugurated in 1944, and the Campaign is launched for a few weeks before Easter each year.

Cripple Care Associations sponsor it in their own regions, on behalf of Council. After the Council's administrative needs and special funds are replenished, $60 \%$ of the remaining net proceeds are automatically returned to these Associations for work in their own area.

The remaining $40 \%$ is allocated as special grants at the discretion of the allocations Committee on which representatives of the Cripple Care Associations also serve.

Extensive propaganda is undertaken by the Council, and through its Easter Stamp Fund organisationalmachinery, by means of press and magazine story/articles, before and after photographs, as well as the 'happy-snaps' type of photos of crippled children; by pamphlets, and by films and talks, throughout the Union and South West Africa.

An interesting example of the effectiveness of this procedure was seen in South West Africa a few years ago. There was no Cripple Care Association but orthopaedic cases came to various centres in the Union for treatment and after care.

Then Council decided to send an organiser up into the territory for a few weeks and such interest was aroused that within two years, a public meeting was arranged, to which a prominent executive member of Council was invited and a fully fledged Cripple Care Association was formed. To-day this very active group is busy with plans for an orthopaedic centre and its negotiations are underway for an orthopaedic surgeon to move to Windhoek in the near future.

Another interesting result of Council's propaganda and negotiations and financial assistance was the first rural orthopaedic clinic being established in 1950 in the Western Transvaal.

To-day there are nine active Cripple Care Associations affiliated to the Council, each having its network of committees. There are just on fifty orthopaedic surgeons in the country; an orthopaedic training course for nurses is conducted by the Council, in collaboration with the Cape Province; practically every large hospital in the Union has its orthopaedic section complete with trained personnel. 
The Cripple Care Associations have after care vomes and case workers who co-operate with clinical services, providing that very essential after-care follow-up without which orthopaedic surgeons have frequently stated the permanent good results of their own work would be retarded or in some cases, seriously offset.

Achievements can then be briefly summarised as follows:

Subsidies toward training and salaries of orthopaedists, orthopaedically trained nurses and technicians, salaries of social workers, transport for personnel; bursaries; physiotherapists and occupational therapy grants toward clinics, orthopaedic centres and wards after-care homes and to other institutions providing orthopaedic service for cripples. It has also contributed a large sum toward the chair of orthopaedics at the Cape Town University.

The Council continues therefore in its work of negotiating with provincial and government departments on all facets of cripple care in South Africa where required and in raising funds toward assisting in this great work.

A layman said recently "Cripples cared for in provincial hospitals would probably not be there at all, if it had not been for the National Council for the Care of Cripples." That is a sweeping statement and very definitely open to challenge, but what Council has done is to suggest, to negotiate, to subsidize, to establish and as funds permit to make grants to help and to maintain and urge Provincial and Government departments to assume responsibility, and when succeeding then to withdraw. Then to start again, in another direction. The network of service for cripples is constantly growing, as new aspects are continually being sponsored by the National Council. One of the latest of these aspects is the need for Non-European Orthopaedically trained nurses, and the Council is negotiating with the government to proceed with a training scheme for this purpose.

\title{
When Ionization is indicated...
}

\section{Imadyl Unction 'Roche'}

\author{
is the substance of choice.
}

\begin{abstract}
Containing $1 \%$ histamine-dihydrochloride
it will produce local effects only and will not cause general vasodilation.
\end{abstract}
Imadyl 'Roche' is freely available again from

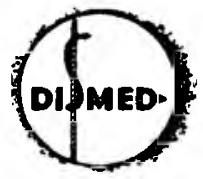

P.O. Box 3378
Medical Distributors: Specialists for Physical Medicine Appliances JOHANNESBURG Telephone 23-8106 236, JEPPE STREET

\section{PHYSIOTHERAPISTS PROGRESS TOWARDS RESPECTABILITY}

Reprinted from the "Manchester Guardian" of September 22nd, 1955.

More than a thousand physiotherapists are expected to attend the annual congress of the Chartered Society of Physiotherapy, which opens at St. Pancras Town Hall, London, to-day. These eminently respectable people are far removed from the rather shady ladies engaged in "medical rubbing" at the end of the century, when the "British Medical Journal" thought it necessary to "warn its readers against the use of massage because of the number of unscrupulous persons practising it.

Indeed, it was because of the dubious reputation of massage at that time that four masseuses, trained at the London Hospital, set out "to make massage a safe, clean, and honourable profession for British women" by sowing the seeds of the present organisation.

How well they have succeeded in changing the doctors' opinions of their speciality can be seen from the important part being played by the physiotherapist in modern medicine. She and he (for men were admitted to the society in 1905) work only under the supervision of a doctor. The physiotherapist makes surgery safer for the patient by preparing him for the operating table. By rehabilitating him after the ordeal she curtails his period of convalescence. She has done much to bring about the current success of fracture surgery, and is now one of a team who are making heart and lung surgery practicable.

There are now almost fifteen thousand members of the society, which is now celebrating this week its diamond jubilee. Among other things they are treating victims of poliomyelitis in this country. They are helping fracture cases in Korea, deformed children in Africa, and victims of rheumatism in Canada, and one of their number has returned from treating lepers in China.

At the congress they will hear a lecture on the place of the physiotherapist in cardiac surgery by Mr. T. Holmes Sellors, and another on the elderly sick by Dr. W. F Anderson. Professor A. R. Knight will talk about "relieving tension in our embodied minds." Mr. G. Perkins will discuss progress in the treatment of fractures, and Dr. J. J. MacQueen the application of "progressive resistance exercise" in physiotherapy, while Dr. H. J. Anderson will lecture on chronic respiratory diseases. For the first time the founder's lecture will be delivered by a physiotherapist, Miss Sybil Evans. There will also be demonstrations of new methods at the meeting and in several London hospitals.

\section{SITUATIONS VACANT}

Required for private practice in Johannesburg, one fulltime Physiotherapist for work in the city and one parttime for work in Rosebank. For particulars, Phone 22-2277.

Required for private practice in Pretoria as soon as possible, a fully qualified Physiotherapist. For further particulars apply P.O. 24, Physiotherapy Department, General Hospital, Johannesburg.

\section{FOR SALE}

M.S.A. PORTABLE COMBINED UNIT, mains operated, black case, giving galvanism, faradism, sinusoidal, with hand surger, £25; also M.S.A. PORTABLE FARADIC UNIT, mains operated, black case, hand surger, $£ 8$. Both are in perfect condition. Apply: 24, St. James' Road, East London. 